\title{
6. DESCRIPTION AND PERFORMANCE OF THE MARINE SEISMIC SYSTEM DURING THE NGENDEI EXPERIMENT ${ }^{1}$
}

\author{
Richard G. Adair, Scripps Institution of Oceanography \\ Michael M. Harris, Naval Ocean Research and Development Activity \\ John A. Orcutt, Scripps Institution of Oceanography \\ and \\ Thomas H. Jordan, Massachusetts Institute of Technology²
}

\begin{abstract}
The Marine Seismic System (MSS) and its performance during the Ngendei Experiment are described. The MSS is a digital, triaxial submarine borehole seismograph that comprises a borehole sensor package connected by coaxial cable to an ocean-bottom recording unit. Two shipboard recording systems provide redundant data logging and instrumentation monitoring capability. One of the shipboard consoles, the Teledyne system, monitored the borehole package. The other, the Gould system, emulated the functions of the ocean-bottom recorder. A submerged mooring facilitates the installation and recovery of the ocean-bottom recorder. The borehole package is emplaced by means of a special carriage tool employed at the bottom end of the drill string. The package rested unclamped at the bottom of DSDP Hole 595B, $54 \mathrm{~m}$ within basement rock overlain by $70 \mathrm{~m}$ of sediments. The hole-lock and cable-isolating mechanisms of the borehole package were disconnected after they were found to damage the coaxial cable. One of the horizontal seismometers was apparently damaged and consequently yielded no usable data. Totals of 120,83 , and 43 hours of data were collected on the Teledyne and Gould shipboard recorders and on the ocean-bottom recorder. The ocean-bottom recorder failed after approximately 2 days of operation because of a water leak in one of its two battery spheres.
\end{abstract}

\section{INTRODUCTION}

The past decade has seen the first use of submarine borehole seismographs in the deep ocean. The earliest employment of such instrumentation was in seismic refraction experiments for elucidating the structure of the oceanic crust and uppermost mantle (see, e.g., Stephen et al., 1980, 1983).

More recently, borehole seismographs have been of interest for use in nuclear discrimination studies because of a hypothesized signal-to-noise advantage gained by borehole emplacement of seismometers over ocean-bottom emplacement. To date, only two borehole seismographs possess sufficient sensitivity to test this hypothesis: the Ocean Sub-bottom Seismograph (OSS) of the Hawaii Institute of Geophysics (Duennebier and Blackinton, 1983), and the Marine Seismic System (MSS) funded by the Defense Advanced Research Projects Agency (DARPA) (Ballard et al., 1984). The OSS has been successfully operated twice, during DSDP Legs 67 (Carter et al., 1984) and 88 (this volume).

A prototype of the MSS tethered to Glomar Challenger was successfully operated during DSDP Leg 78B (Ballard et al., 1984). This chapter describes the first deployment of the fully operational MSS during DSDP Leg 91, which composed a portion of the Ngendei Experiment.

\footnotetext{
${ }^{1}$ Menard, H. W., Natland, J., Jordan, T. H., Orcutt, J. A., et al., Init, Repts, DSDP, 91: Washington (U.S. Govt. Printing Office).

2 Addresses: (Adair, Orcutt) Institute of Geophysics and Planetary Physics, Scripps Institution of Oceanography, La Jolla, CA 92093 (Adair, present address: Rockwell Hanford Operations, Energy Systems Group, P.O. Box 800, Richland, WA 99352); (Harris), Naval Ocean Research and Development Activity, NORDA Code 500, NSTL Building 1100 , Bay St. Louis, MS 39529 (Jordan) Department of Earth, Atmospheric, and Planetary Sciences, Massachusetts Institute of Technology, Cambridge, MA 02139.
}

\section{MARINE SEISMIC SYSTEM DESCRIPTION}

The MSS is the culmination of a multicorporation development program coordinated by the Naval Ocean Research and Development Activity (NORDA) at the behest of DARPA.

When fully operational, the MSS comprises a borehole sensor package connected by coaxial cable to an untended ocean-bottom recording system (Fig. 1). The borehole package and a companion shipboard recording console, referred to here as the Teledyne system, were developed by Teledyne-Geotech. The ocean-bottom recording system and its shipboard counterpart, referred to as Gould systems, were developed by Gould, Inc. Global Marine Development Corporation built a carriage for transporting the borehole package to the seafloor at the bottom end of the drill string. The Naval Civil Engineering Laboratory in Port Hueneme, California, designed and tested a submerged mooring that facilitates the installation and recovery of the ocean-bottom recording system.

Transcriptions of the original MSS data are available on nine-track tape from DARPA's Center for Seismic Studies in Alexandria, Virginia. The Center for Seismic Studies was developed as a pilot data collection and analysis facility in compliance with nuclear arms limitation treaties, which call for the rapid dissemination of seismic data to be used in treaty verification (Berger et al., 1984).

\section{MSS Instrumentation}

Figure 2 depicts the cylindrical borehole sensor package. The instrumentation is housed in a $609.6-\mathrm{cm}-$ long pressure vessel of $20.3 \mathrm{~cm}$ OD. The instrumentation in- 


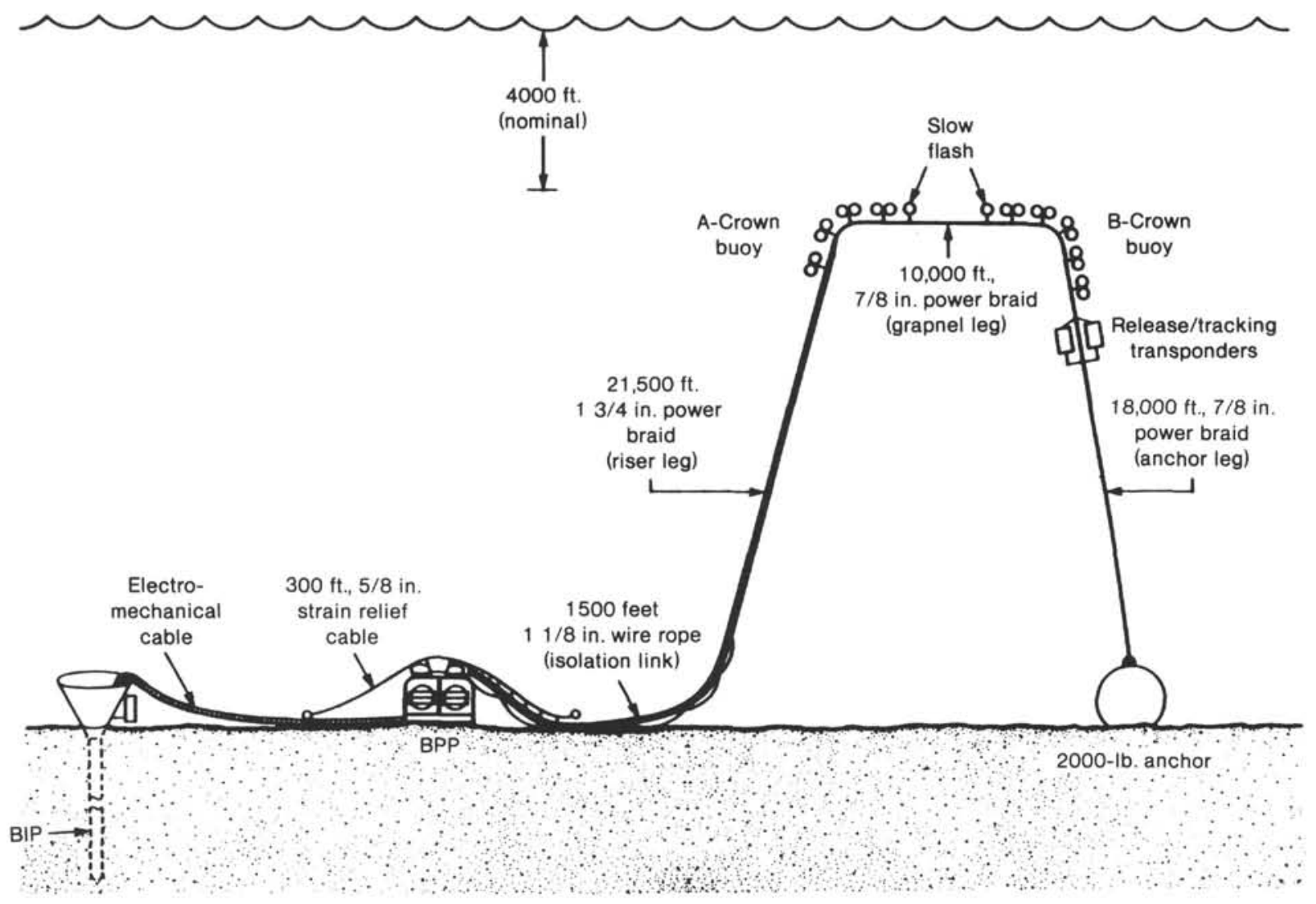

Figure 1. Cartoon of the MSS configuration as deployed on the seafloor. The borehole instrumentation package (BIP) is connected to the ocean-bottom recording system (the BPP, Bottom Processing Package) by a mechanically strong coaxial cable. The BPP in turn is connected to a $15.7-\mathrm{km}$ submerged mooring that permits its emplacement and recovery.

cludes seismic sensors, accelerometers, and internal pressure and temperature monitors. Above the pressure vessel is a 343.9-cm-long cable terminator unit, and below it, a 43.8-cm-long impact tip. The cable terminator incorporates cable-isolating and hole-lock mechanisms.

The MSS sensors are four Teledyne model S-750 seismometers configured as a triaxial set (two orthogonal horizontals and one vertical) and a redundant backup vertical component. The backup sensor is located 175.5 $\mathrm{cm}$ below the primary vertical sensor. Output from the three primary sensors is filtered in midperiod $(0.5-10 \mathrm{~s})$ and short-period $(0.05-2 \mathrm{~s})$ bands, whereas output from the backup sensor is passed through the short-period only. The resultant seven data streams are then digitized and transmitted to the recording devices via coaxial cable. For convenience, the sensors and data channels are labeled in subsequent discussion. The horizontal sensors are $\mathrm{X}$ and $\mathrm{Y}$, and the primary and backup verticals are $\mathrm{Z}$ and B, respectively. The prefixes "S" and " $M$ " will refer to the passband of a particular channel.

\section{MSS Recording Systems}

The MSS data are collected on either two shipboard systems employed for diagnostic checkout and recording redundancy or on an ocean-bottom recording unit. The Gould systems differ vastly from the Teledyne system in their digitizing scheme and post-digitizing processing method. Briefly, the Teledyne system samples the data after low-passing them, whereas the Gould systems con- volve the data with a digital low-pass filter after sampling them at an extremely high rate to avoid aliasing. The Gould data are resampled at the desired rate following the convolution.

\section{Teledyne Shipboard Recorder}

Data destined for the shipboard Teledyne system are sampled, amplified at one of four gains $(\times 1, \times 8, \times 32$, and $\times 128$ ), and represented as 14-bit integers augmented by a 2 -bit gain code. Each datum is separately amplified, thereby achieving a 21-bit dynamic range with 14bit resolution. Midperiod data are routinely digitized at 4 samples/s, and the short-period data at 40 samples/s, although either of the short-period vertical channels may be sampled 80 samples/s by excluding the other.

The Teledyne multiplexing method introduces an appreciable timing skew into the data because of the sequential sampling of the different data channels. This skew, which may amount to as much as $0.5 \mathrm{~s}$, is preserved in the nine-track transcriptions of the data. The seismic data are formatted for transmission in 1-s frames. A frame comprises 20 sub-frames of 12 words ( 16 bit), a total of 240 words. Words 1 and 2 of the subframes compose a synchronization pattern, words 3-6 and 9-12 are short-period data, word 7 is a midperiod datum, and word 8 is a state-of-health datum. The three midperiod channels are consecutively sampled once per subframe over five subframes in the order $\mathrm{Y}, \mathrm{X}$, and $\mathrm{Z}$. The shortperiod data are sampled twice per subframe in every sub- 


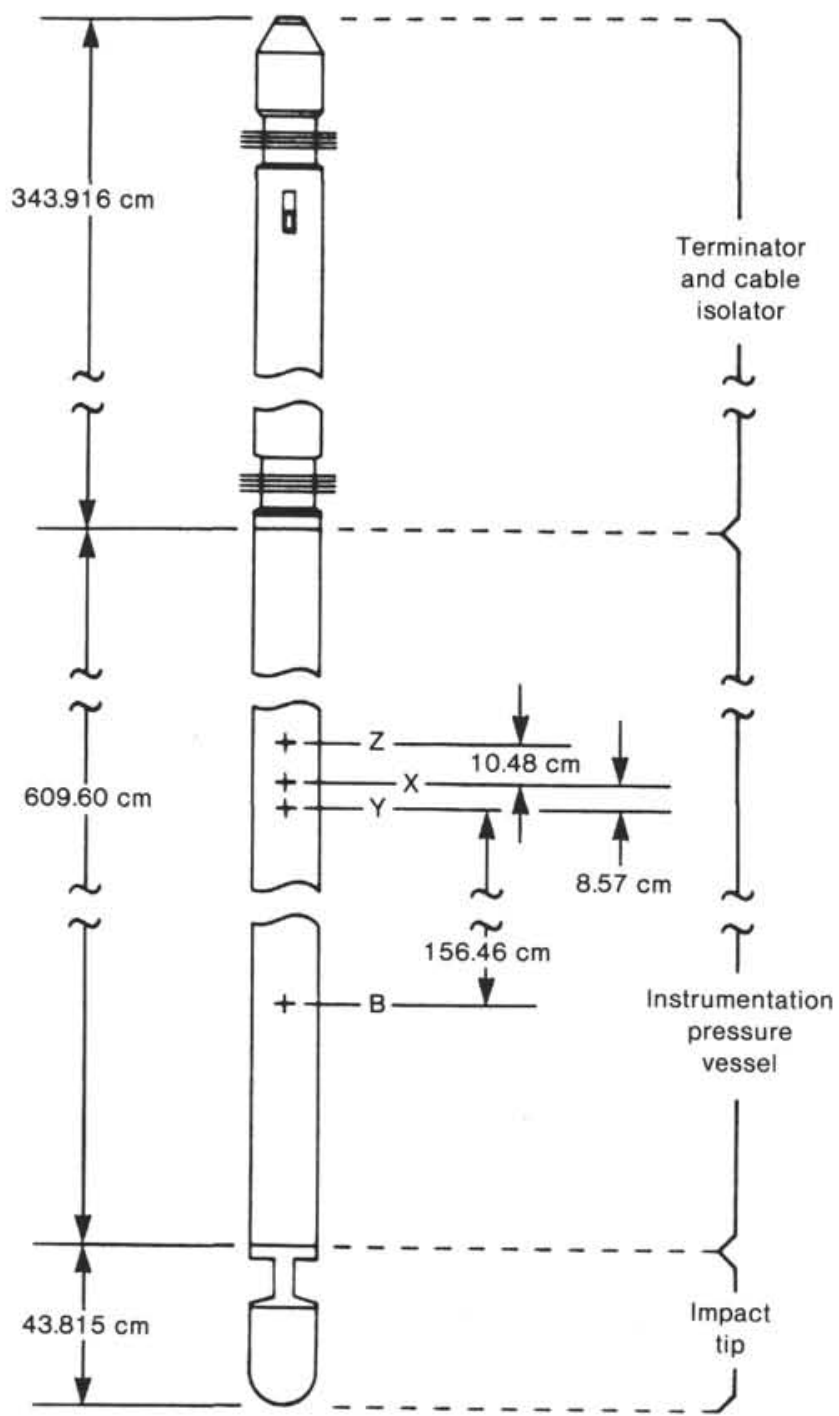

Figure 2. Schematic representation of the borehole instrumentation package showing the seismic sensor locations.

frame in the order Z, X, Y, B. The mid-period data times are consequently skewed by the duration of one subframe $(1 / 20 \mathrm{~s})$, and the short period by one subframe word (1/ $240 \mathrm{~s})$. The skewed times are written with the data. When one of the vertical components is sampled 80 times/s, it replaces the other in the sampling scheme.

The shipboard Teledyne system records the seismic data and timing information generated downhole as a digital stream. This stream may be applied to a data decomutator for diagnostic display and from there to a strip-chart recorder. A standard time code synchronized with Greenwich Mean Time (GMT) may be written simultaneously with strip-chart data.

\section{Gould Shipboard and Ocean-Bottom Recorders}

Data transmitted to the ocean-bottom recorder and its shipboard counterpart are represented with an enhanced delta modulator encoding technique that yields high resolution and low sampling noise. Basically, the digitizing method (see, e.g., Claasen et al., 1980) oversamples (by 256 times) the integrated signal, which, af- ter transmission, is recovered from first differences of the digital data. The resulting sampling noise spectrum is proportional to the ratio of frequency and the oversampling factor. Hence, an appropriate choice of the oversampling factor ensures that sampling noise is sufficiently small over the desired passband and that the dynamic range is increased over that of the straightforward digital amplitude representations used by the OBSs and the Teledyne system. The increased digital resolution is due in part to the lower sampling noise levels, and in part to the fact that amplitude differences, rather than amplitudes, are being sampled. In principal, the digital data have 24-bits of both dynamic range and resolution.

The encoded, oversampled streams are transmitted to the recording unit where they are digitally convolved with a low-pass, zero phase-shift filter. The oversampling prevents aliasing prior to application of the digital low-pass filter by taking advantage of the falloff of the instrument response at high frequencies. The filter amplitude response is nearly flat below $75 \%$ of the ultimate Nyquist frequency, and thereafter falls at approximately $750 \mathrm{~dB}$ / decade. The midperiod and short-period filter coefficients computations differ only in the assumed sampling rate.

The filter weights are modifications of coefficients computed by a published signal processing program (see McClellan et al., 1973). Each of the resultant filter weights, generated assuming 8-fold oversampling, is padded with 31 zero weights to achieve the 256 -fold oversampling. Sixfold convolution with a 32-point boxcar suppresses unwanted peaks in the filter's amplitude spectrum introduced by the zero padding. This convolution is equivalent to multiplying the filter's amplitude spectrum by $\sin c^{6}(f / 320)$, where $\sin c(x) \equiv \sin (\pi x) /(\pi x)$. Prior to this, however, the weights are smoothed with a threepoint running mean (weights of $-0.25392,+1.50784$, and -0.25392 ) to compensate a droop within the desired passband introduced by the subsequent boxcar convolutions.

The low-passed digital data are resampled at their proper rates and buffered to tape with timing and system status information. The rich oversampling obviates timing skew $(1 / 256$ of a sample interval), which is therefore neglected. Midperiod data are recorded at a rate of 4 samples/s and the short-period data at 40 samples/s.

The Gould ocean-bottom recording system (Fig. 3) employs 20 tape drives to achieve a 45 -day maximum operating period. Power is provided by two battery packs. Each of the packs and the data processing electronics are housed in separate aluminum spheres $5.08 \mathrm{~cm}$ thick and $85.1 \mathrm{~cm}$ ID. The three spheres and various hydroacoustic instrumentation are mounted on an aluminum framework. A sediment-penetrating flange rimming the framework bottom secures the recorder package on the seafloor. Recorder recovery is aided by the corrosion of magnesium-alloy bolts binding the flange, which allow the superstructure's detachment.

\section{MSS Instrument Response}

Figure 4 shows the instrument responses of the MSS systems. The dashed lines at high frequencies depict the effect of the Gould low-pass filter. In the absence of this 


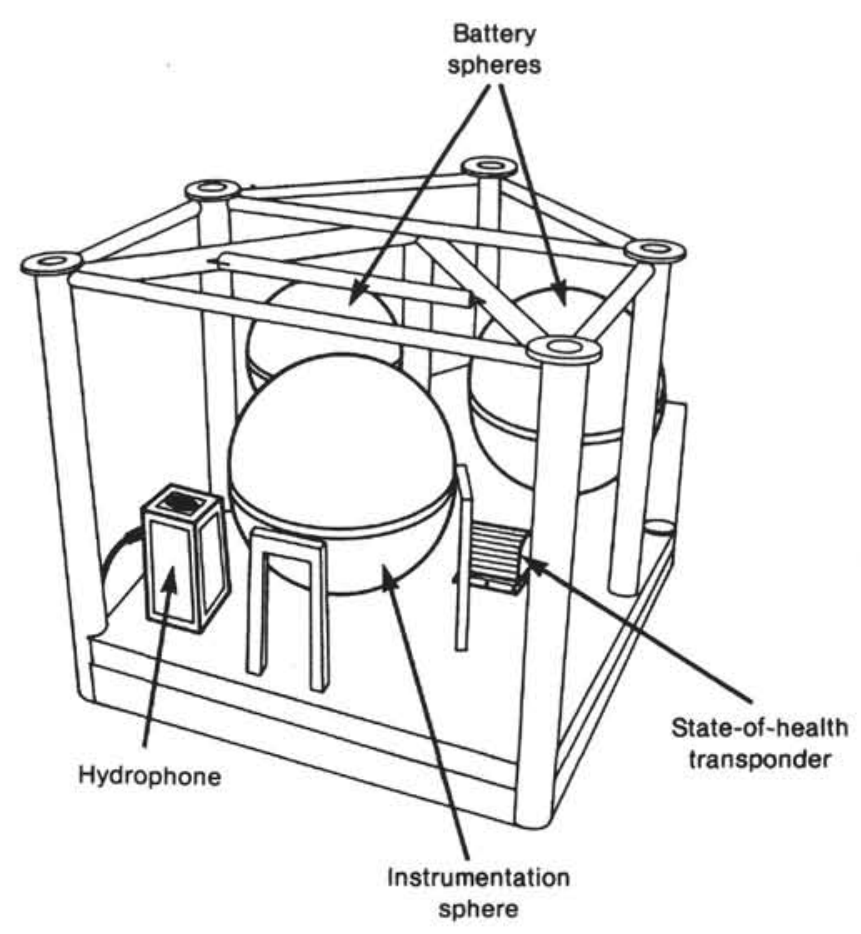

Figure 3. External view of the MSS's ocean-bottom recording system. Most of its recording and control instrumentation are located in the foreground sphere. The two rear spheres hold zinc-silver batteries. Mounted on the recorder's base is a short-period hydrophone and an acoustic transponder. The transponder permits monitoring of recorder status and depth during its deployment.

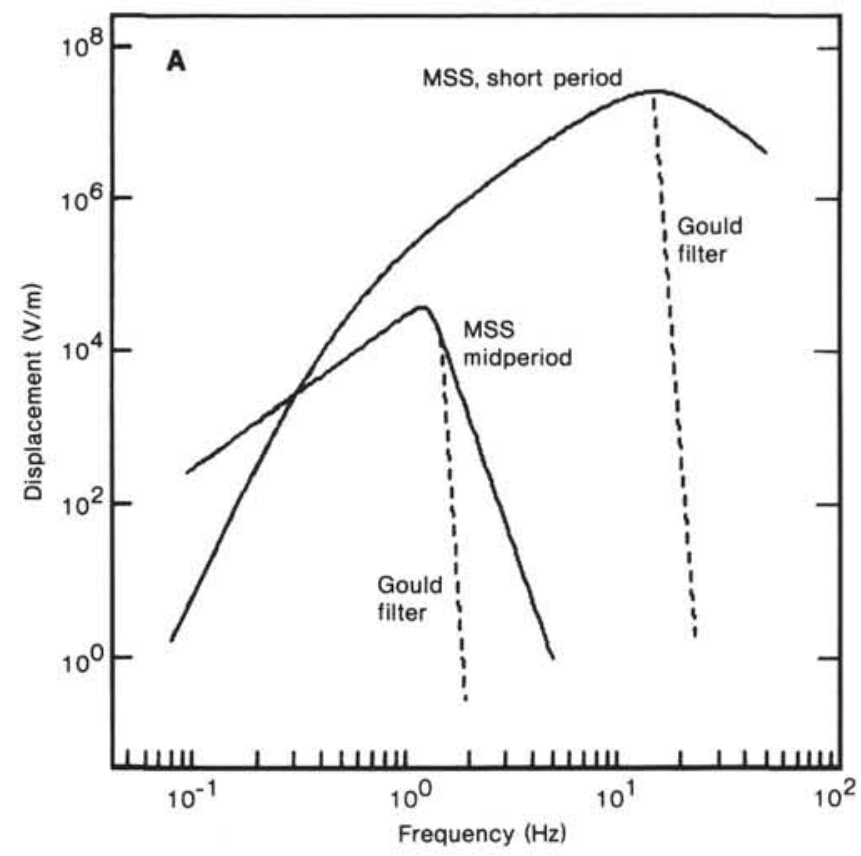

Figure 4. Displacement responses of the MSS. The Gould and Teledyne systems have identical responses over both midperiod (MP) and short-period (SP) bands below 1.5 and $15 \mathrm{~Hz}$, respectively. Above these frequencies the Gould systems are augmented by a low-pass, digital filter. The Nyquist frequencies for the MP and SP bands are 2 and $20 \mathrm{~Hz}$, respectively. low-pass filter, the midperiod response is peaked at approximately $1.2 \mathrm{~Hz}$ and falls off at 40 and $150 \mathrm{~dB} / \mathrm{dec}-$ ade toward lower and higher frequencies, respectively. The short-period response is peaked at approximately 15 $\mathrm{Hz}$ and declines gently toward lower and higher frequencies at 40 and $45 \mathrm{~dB} /$ decade, respectively. At the midperiod Nyquist frequency, $2 \mathrm{~Hz}$, the midperiod response is down $28 \mathrm{~dB}$ from its peak. At $20 \mathrm{~Hz}$, the short-period response is down only $1.5 \mathrm{~dB}$ from its peak, while at 40 $\mathrm{Hz}$, the Nyquist frequency in the case of the $80 \mathrm{sam}-$ ples/s mode on the Teledyne system, the response is down $11.5 \mathrm{~dB}$. As mentioned before, the Gould low-pass filter falls at approximately $750 \mathrm{~dB} /$ decade beyond $75 \%$ of the Nyquist frequencies.

\section{Deployment and Recovery Tools}

Special tools and equipment facilitate deployment and retrieval of the MSS. A reentry sub (i.e., substitute drillstring section) employed at the drill string's bottom end installs the BIP, the outer diameter of which prohibits its deployment within the drill string. A $15.7-\mathrm{km}$-long mooring facilitates BPP emplacement and retrieval. The various MSS-related cables and lines are passed from a winch through a sheave block mounted on a heave-compensated A-frame equipped with tension monitors. A network of acoustic transponders facilitates MSS location and recovery.

The reentry sub (Fig. 5) comprises the BIP carriage, carriage housing, stinger, control sub, packer/sonar tool adaptor, and release hydraulics. The carriage, bearing the BIP with the coaxial cable attached, rides to the seafloor in the off-axis carriage housing and is shifted onaxis with the release hydraulics after the sub's stinger tip is seated in the reentry cone throat. During the trip down, the cable is arced downstream of the drill string to avoid entanglements. When the reentry sub nears the ocean bottom, a sonar tool is lowered through the drill string and reentry sub to guide the stab into the cone, where the stinger assembly directs and seats the sub in the cone throat. The sonar tool is then retrieved and a packer lowered to the control sub at the top of the reentry sub to activate the release hydraulics. The packer/sonar tool adaptor is subsequently raised from the stinger tip to the control sub where it seals the hydraulics. The hydraulics shear aluminum release pins and shift the BIP carriage over the borehole. Coaxial cable payout then lowers the BIP to the hole bottom. After the reentry sub is raised clear of the cone, the hydraulics actuate release of the cable from a protective sheath in the stinger. The cable is then freed through a slit running the entire length of the reentry sub. The cable is of sufficient mechanical strength to be winched-in for BIP recovery and is therefore referred to as electromechanical (EM) cable.

When deployed with the ocean-bottom recorder package at one end and a clump anchor at the other, the submerged mooring has a roughly trapeziform configuration (see Fig. 1) with its crown (a grapnel leg) buoyed by floats at either vertex. The mooring comprises, in order, an isolation link of $2.9-\mathrm{cm}(11 / 4 \mathrm{in}$.) wire cable, a riser leg of 4.4-cm (1 3/4-in.) power braid, and grapnel and anchor legs of $2.2-\mathrm{cm}(7 / 8$-in.) power braid. The ap- 

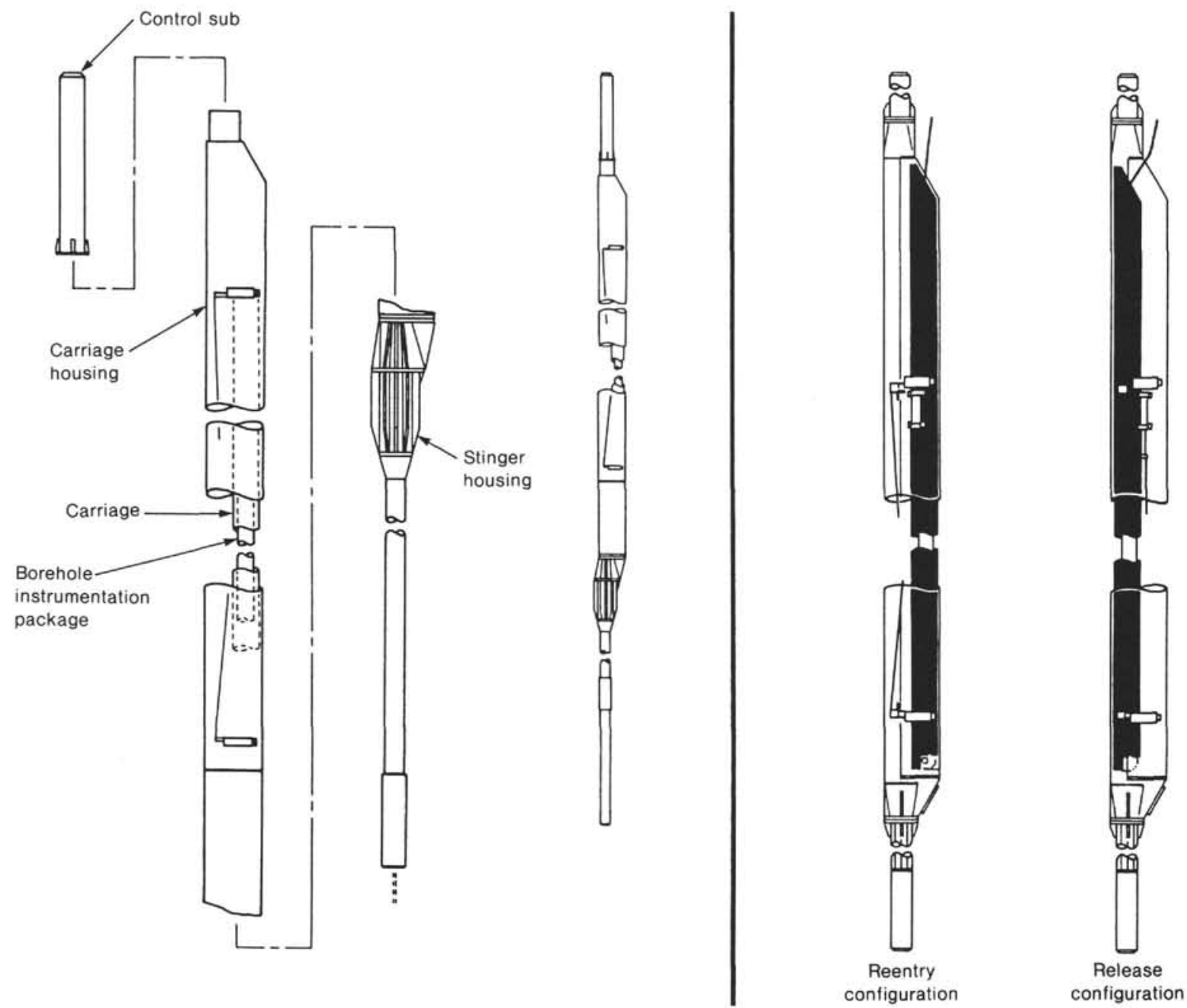

Figure 5. Schematic illustration of the reentry tool used to install the borehole package. The left portion of this figure shows an exploded view of the tool, and the right portion shows the configuration of the borehole package in the tool at reentry and release.

proximate lengths of these segments are, respectively, 0.5 , $6.6,3.1$, and $5.5 \mathrm{~km}$, a total of $15.7 \mathrm{~km}$. A pair of release mechanisms equipped with ATNAV transponders links the grapnel and anchor legs, whereas all other mooring segments are spliced. The transponders and flashing beacons at each of the crown vertices aid in finding the mooring location once the grapnel leg surfaces.

\section{OPERATIONS}

Figure 6 charts a select chronology of operations and events. The events of the Ngendei Experiment are conveniently segregated into three phases according to whether or not the Gould ocean-bottom recorder was in use. These three phases also roughly demark periods during which the tending ships Glomar Challenger and Melville were or were not present. Challenger was responsible for installation of the MSS sensors and seafloor recorder, and Melville conducted MSS support operations, site surveys, and instrumentation recovery as well as all OBS operations. The ships were absent only during the second phase.

The 20-day-long first phase included site selection, borehole drilling, instrumentation deployment, and a re- fraction experiment. The second phase comprised a 40day period of untended earthquake and noise recording. The instrumentation was recovered during the final phase.

Deployment of the primary borehole instrumentation package (BIP) commenced on 1 February, but was aborted at $1428 \mathrm{Z}$, 1 February 1983 , when, after tripping only $213 \mathrm{~m}$ of drill string, an instrumentation malfunction was detected (Fig. 6, point 1a). The malfunction was attributed to EM cable damage caused by the cable isolator in the terminator.

A backup BIP, BIP-2, was subsequently deployed without the cable isolator. In addition, an associated holelock arrangement and a series of motion-retarding rubber disk collars were disconnected, both to avoid possible cable damage and to improve the package's fit within the reentry sub. Deployment of the backup package proceeded without incident, although the reentry tool's stinger (see Fig. 5) was missing upon recovery. The bolts that bound the stinger to the rest of the tool were sheared off.

The triaxial accelerometers in BIP-2 apparently malfunctioned. No acceleration observations exceeding $1 \mathrm{~g}$ $(9.8 \mathrm{~m} / \mathrm{s} / \mathrm{s})$ were measured, an unlikely situation in light 


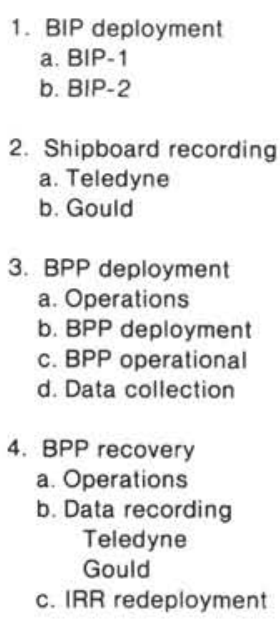

5. Refraction lines

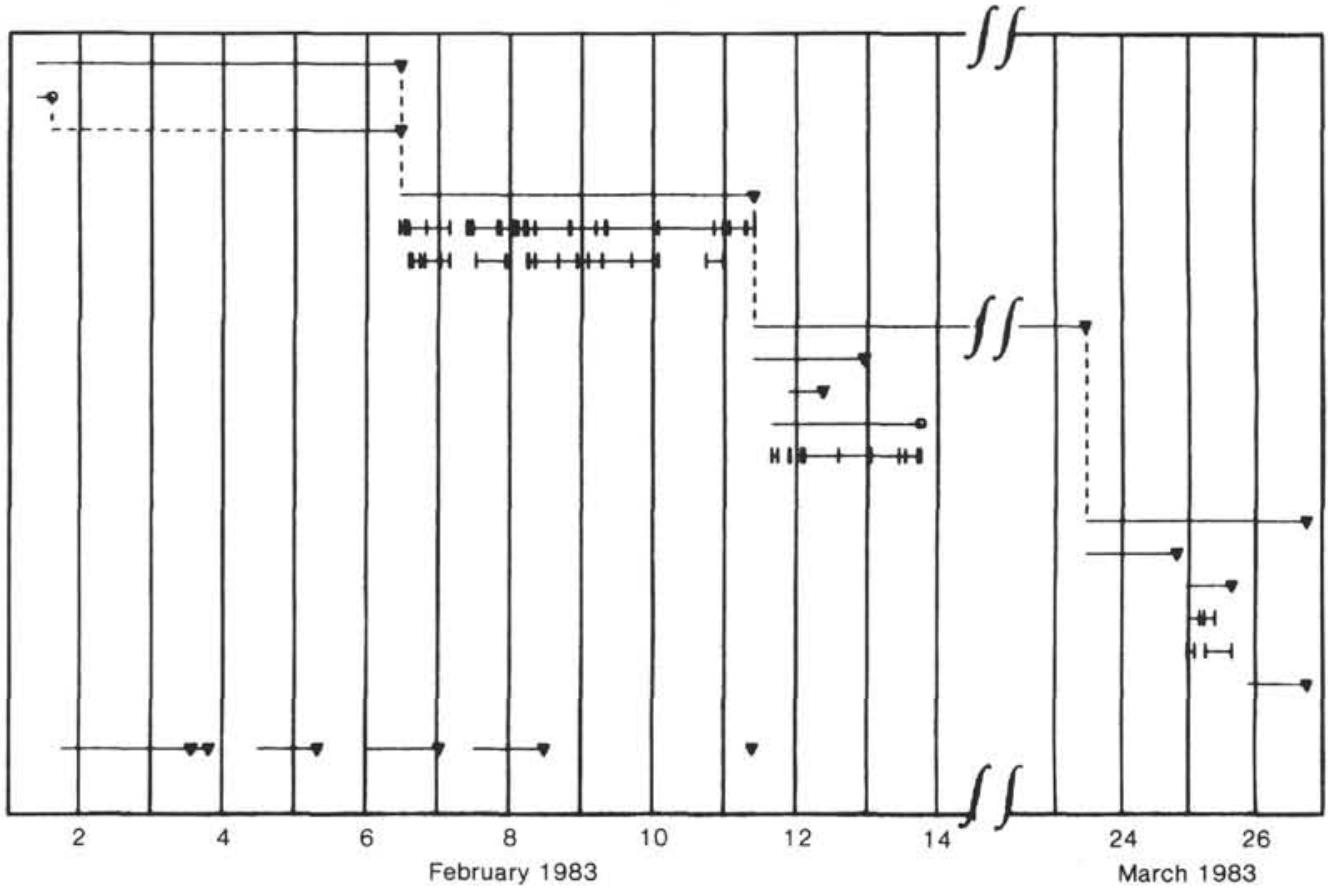

Figure 6. Chronology of events during the MSS deployment. GMT date is given along the bottom axis. See text for explanation.

of accelerations on the order of $3 g$ 's experienced by a prototype BIP installed during DSDP Leg 78B (Ballard et al., 1984). Acceleration data would have been useful in ascertaining why the bolts binding the stinger sheared.

The borehole package was installed at the bottom of DSDP Hole 595B, a depth of $124 \mathrm{~m}$ below the seafloor, $54 \mathrm{~m}$ into the basement rock. As previously noted, the hole-lock mechanism was not operative, so that the package was not clamped in place. However, the large mass and small cross section of the package probably allow for adequate coupling to the hard basement rock. In addition, approximately $0.5 \mathrm{~km}$ of slack cable were payedout onto the seafloor to quell motions of the cable.

A 5-day period of on-deck recording of seismic data commenced at $1110 \mathrm{Z}, 6$ February (Fig. 6 , point 2 ). Data were continuously recorded except for breaks caused by system maintenance or malfunction. Channel SZ of the Gould system was not used because an unknown shipboard source of electrical noise dominated its output. Sensor calibrations indicated Y-sensor malfunction. During this on-deck period, the Teledyne system collected approximately $114 \mathrm{hr}$. of seismic data $(1000 \mathrm{Z}, 6 \mathrm{Feb} .-$ $0957 \mathrm{Z} 11 \mathrm{Feb}$.), and the Gould system approximately 71 hr. (1200Z, 6 Feb.-2357Z, 10 Feb.) (Fig. 6, points 2a, $2 b)$. These data include observations of ambient noise, earthquakes, and signals from refraction shots, many of which were simultaneously recorded on a proximate array of six OBSs.

Deployment operations of the ocean-bottom recording unit, the Bottom Processing Package (BPP), began at $0235 \mathrm{Z}, 11 \mathrm{Feb}$. (Fig. 6, point 3a). The recording unit touched down on the seafloor at 0920Z, 12 Feb. (Fig. 6, point $3 b$ ).

Installation operations ended at $2311 \mathrm{Z}, 12 \mathrm{Feb}$. with the confirmed emplacement of the mooring in the con- figuration shown in Figure 7. Also shown are locations of the various navigational transponders.

Data recording on the ocean-bottom unit started at 2142Z, 11 February (Fig. 6, point 3d) while the unit was still on deck (Fig. 6, point $3 \mathrm{~b}$ ) and continued for approximately 43 hours. Recording ended at $1805 \mathrm{Z}, 13$ February, when a water leak in one of the power spheres caused a total shutdown.

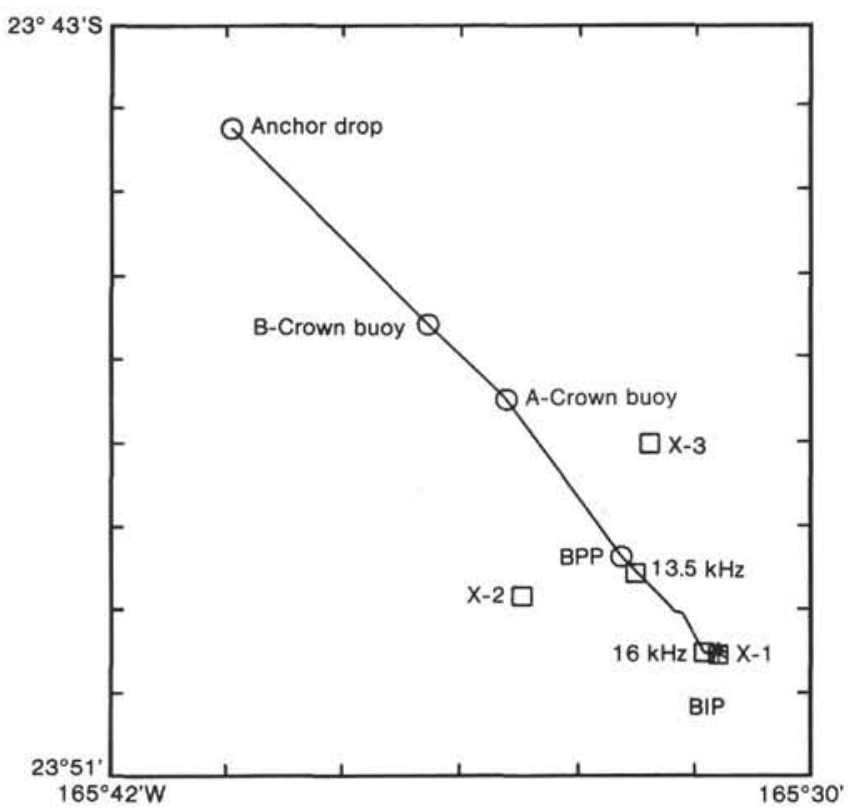

Figure 7. Configuration of the MSS as actually deployed. The site of the borehole package, DSDP Hole 595B, is denoted by an asterisk. Portions of the ocean-bottom recorder (BPP) and its mooring are denoted by circles. Navigational transponders are given by boxes. 
A Gould electronics bay of the borehole package that contained both the calibration initiator and the channel $\mathrm{MZ}$ digitizer failed sometime after the transfer of the coaxial cable from the Teledyne shipboard recorder to the ocean-bottom recorder. This failure was discovered before the ocean-bottom recorder entered the water. Calibrations could thereafter be initiated only by the Teledyne console, and Gould channel MZ data were not available.

MSS recovery operations (Fig. 6, point 4 a) proceeded smoothly following the successful recovery of the six OBSs. The ocean-bottom recorder was brought aboard the Melville at 1934Z, 24 March, at which time the recorder's power failure was discovered. A further period of on-deck data recording (Fig. 6, point 4b) began shortly after this, yielding approximately 5.5 and 12.75 hours of data from the Teledyne and Gould shipboard systems. The mooring was redeployed with the load of the ocean-bottom recorder replaced by a concrete clump anchor (Fig. 6, point 4c). The instrumentation package remains in DSDP Hole 595B.

\section{MSS DATA CHARACTERISTICS}

Detailed analyses of the MSS data are presented in other chapters in this volume. In particular, ambient earth noise (Adair et al., this volume), signal and noise characteristics (Shearer et al., this volume), and signals from a refraction experiment (Whitmarsh et al., this volume) are examined. In the following, only data limitations caused by system characteristics or instrumentation malfunction are presented.

Transcriptions of the MSS data are available on ninetrack tape from the DARPA-funded Center for Seismic Studies (see Berger et al., 1984, for a brief description). The transcribed Teledyne data have been corrected for the clock drift shown in Figure 8. Gould shipboard data timing was slaved to Teledyne's. Data timing in Gould's ocean-bottom recorder, maintained by internal clocks,

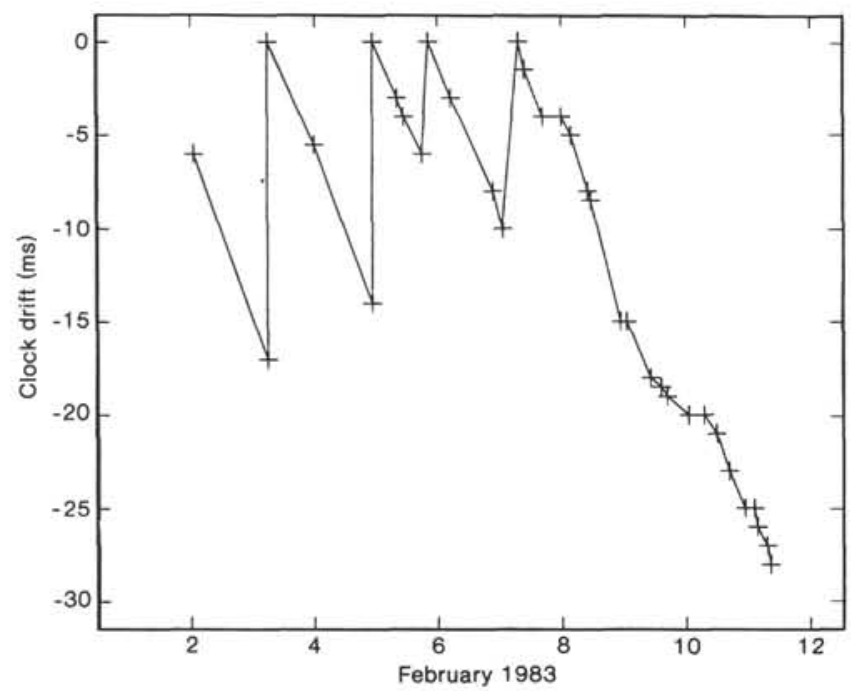

Figure 8. Clock drift of the Teledyne system during the shipboard recording period. A drift value of zero indicates that clock was reset to GMT. was erroneously set at recorder deployment to $6 \mathrm{hr}$. earlier than GMT time. Consequently $6 \mathrm{hr}$. must be added to the time given in the transcriptions of these data.

Figures 9 and 10 depict a typical sample of the Teledyne and Gould system recordings. The data means have been removed before being plotted, a particularly essential step for the 24-bit Gould data, in which signal amplitudes are two to three orders of magnitude smaller than the digital DC offset. The noisy, transient-ridden character of both passbands of the Y sensor as well as their insensitivity to signal apparent on all other channels is caused by sensor malfunction. Sensor malfunction is also indicated by the mismatch observed in the Teledyne sensor calibrations of channels SY and MY (Fig. 11) during both the installation and recovery shipboard recording periods. All other midperiod channels were well calibrated between 0.2 and $1.0 \mathrm{~Hz}$, and the other short-period channels were well calibrated between $\mathbf{0 . 2}$ and $15 \mathrm{~Hz}$.

The Teledyne and Gould data are relatively skewed in timing and amplitude. The timing skew amounts to a nominal 16-sample delay of the Gould data with respect to the Teledyne data on both the short-period and midperiod channels. Comparison of refraction signals recorded on the Teledyne system with analog tracings on which WWV timing is superposed indicate that the Gould data timing is in error.

The amplitude mismatch is evident from least-squares fits of Gould data, corrected for the aforementioned timing skew, against Teledyne data. The ratio of Teledyne and Gould amplitudes is approximately $3 \mathrm{~dB}$ lower than that expected from dynamic range differences of their digital word lengths. Gould amplitudes should be 8 times greater that Teledyne amplitudes, but are observed to be only approximately 5.5 times greater. Teledyne sensor calibrations are within $3 \mathrm{~dB}$ of the calculated norm, implying that Gould amplitudes are in error.

Short-period recordings of signals from near shots (within $10 \mathrm{~km}$ ) on the Gould system (Fig. 12, between 0.1 and $0.35 \mathrm{~s}$ ) display a prominent $18 \mathrm{~Hz}$ (approximately) precursor to water waves that is absent in Teledyne data and precedes any possible physical arrival. The Gould low-pass filter is most likely responsible for these acausal oscillations because it is a zero-phase shift, digitally implemented filter. The precursor's frequency is near the filter's extremely sharp corner at $15 \mathrm{~Hz}$.

Also evident in Figure 12, between 0.5 and $0.6 \mathrm{~s}$, is Teledyne data aliasing. Peaks of the oscillation just after the largest amplitudes of the water wave that are present in the Teledyne data (dashed), but not the Gould data (solid), occur at the sampling rate.

\section{SUMMARY AND CONCLUSIONS}

The components of a marine borehole seismograph system, the MSS, and their performance during the Ngendei Experiment have been described. The MSS comprises a borehole instrumentation package connected by coaxial cable to an ocean-bottom recording system. Data were also recorded by two shipboard consoles - one (the Gould system) emulated most of the ocean-bottom recorder's capabilities, and the other (the Teledyne system) provid- 


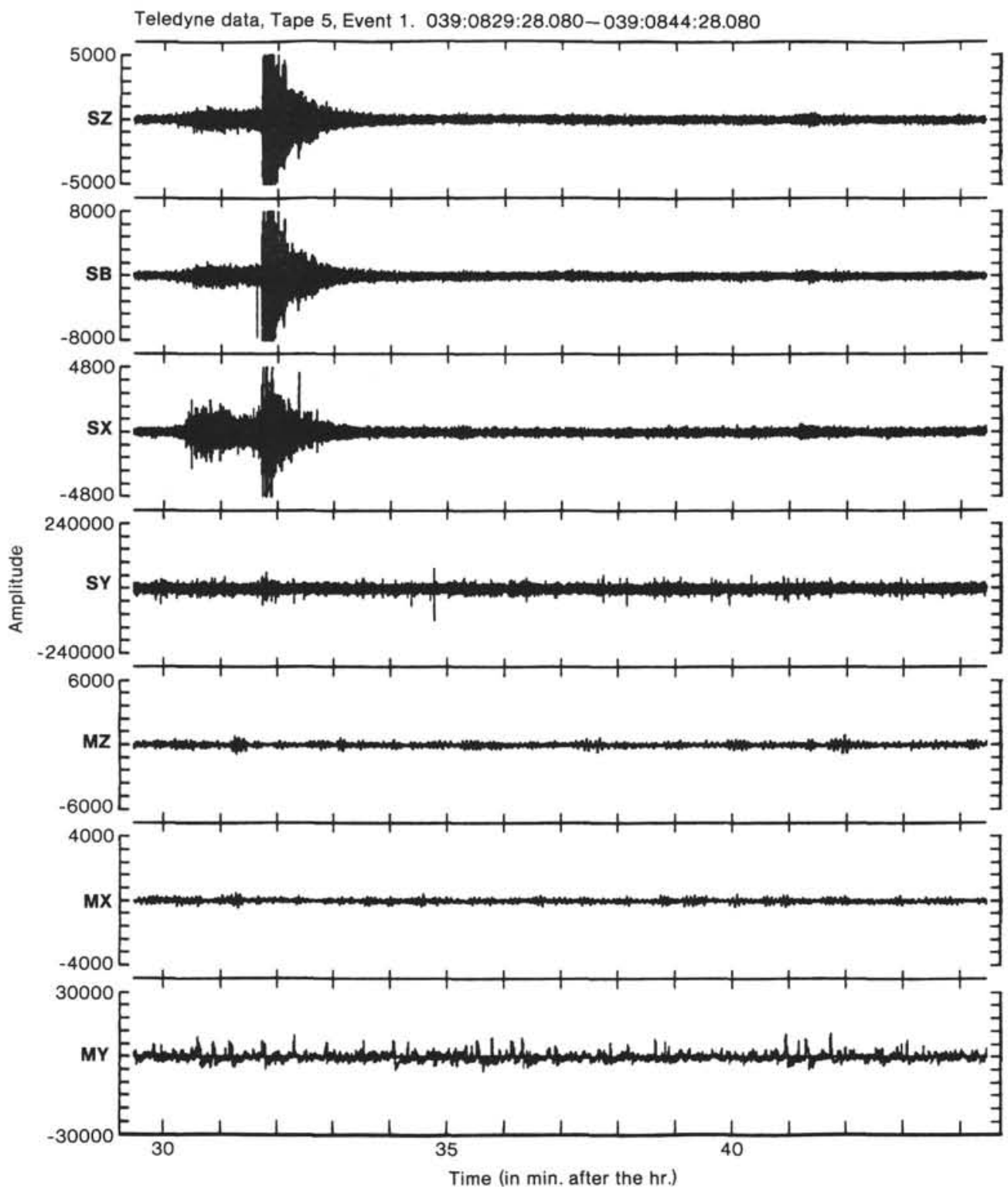

Figure 9. Typical example of seven-channel data from the Teledyne. The recording interval is listed across the top and the time in minutes after the hour is given across the bottom. Channel identifications and amplitudes in digital counts are along the left-hand side.

ed redundant data logging and borehole package monitoring.

The borehole package rested unclamped at the bottom of Hole 595B approximately $54 \mathrm{~m}$ within basement rock overlain by $70 \mathrm{~m}$ of sediment. The package's holelock mechanism was disconnected to prevent possible coaxial cable damage. However, $0.5 \mathrm{~km}$ of slack cable was payed out on the seafloor to dampen cable motions.

Approximately 120 and $84 \mathrm{hr}$. of data were recorded by the Teledyne and Gould shipboard systems, respectively. The Gould ocean-bottom recording system failed after collecting approximately $43 \mathrm{hr}$. of data.

Although the MSS ocean-bottom recording system malfunctioned shortly after emplacement and therefore precluded the long-term earthquake and noise studies, the large amount of digital data retrieved from the various MSS recording systems, approximately 5 days from each, are sufficient to address the goals of the Ngendei Experiment. With the exception of the cable-isolating and holelocking mechanisms of the borehole package, the installation and operational procedures of the various MSS components were effective. The Gould recording scheme suffered from several peculiarities, the most serious of which was the introduction of an acausal signal by its digitally implemented low-pass filter.

\section{ACKNOWLEDGMENTS}

The authors thank Steven Constable for his useful comments. This research was supported by DARPA contracts F49620-79-C-0019 and AFOSR-84-0043.

\section{REFERENCES}

Adair, R. G., Orcutt, J. A., and Jordan, T. H., 1984. Analysis of ambient seismic noise recorded by downhole and ocean bottom seismometers on Deep Sea Drilling Project Leg 78B. In Hyndman, R. 
D., Salisbury, M. H., et al., Init. Repts. DSDP, 78: Washington (U.S. Govt. Printing Office), 767-781.

Ballard, J. A., Mulchahy, C. C., Wallerstedt, R. L., and Kiser, E. L., 1984. The borehole seismic experiment in Hole 395A: Engineering and installation. In Hyndman, R. D., Salisbury, M. H., et al., Init. Repts. DSDP, 78: Washington (U.S. Govt. Printing Office), 743-758.

Berger, J., North, R. G., Goff, R. C., and Tiberio, M. A., 1984. A seismological data base management system. Bull. Seism. Soc. Am., $74: 1849-1862$.

Carter, J. A., Duennebier, F. K., and Hussong, D. M., 1984. Comparison between a downhole seismometer and a seismometer on the ocean floor. Bull. Seism. Soc. Am., 74: 763-772.

Claasen, T., Wolfgang, A. C. M., Mechlenbraüker, F. G., Peek, J. B. H., and van Hurck, N., 1980. Signal processing method for improving the dynamic range of $\mathrm{A} / \mathrm{D}$ and $\mathrm{D} / \mathrm{A}$ converters. IEEE Thans. Acoust., Speech, Signal Processing, ASSP-28, 5:529-537.
Duennebier, F. K., and Blackinton, G., 1983. The ocean subbottom seismometer. In Geyer, R. (Ed.), Geophysical Exploration at Sea: Boca Raton, FL. (CRC Press), pp. 317-332.

McClellan, J, H., Parks, T. W., and Rabiner, L. R., 1973. A computer program for designing optimum FIR linear phase digital filters. IEEE Trans. Audio, Electroacoust., AU-21, 506-525.

Stephen, R. A., Louden, K. E., and Matthews, D. H., 1980. The oblique seismic experiment on Deep Sea Drilling Project Leg 52. In Donnely, T. Francheteau, J., Bryan, W., Robinson, P., Flower, M., Salisbury, M., et al., Init. Repts. DSDP, 51, 52, 53, Pt. 1: Washington (U.S. Govt. Printing Office), 675-704.

Stephen, R. A., Johnson, S., and Lewis, B., 1983. The oblique seismic experiment on Deep Sea Drilling Project Leg 65. In Lewis, B. T. R., Robinson, P., et al., Init. Repts. DSDP, 65: Washington (U.S. Govt. Printing Office), 675-704.

Date of Initial Receipt: 28 March 1985

Date of Acceptance: 28 January 1986

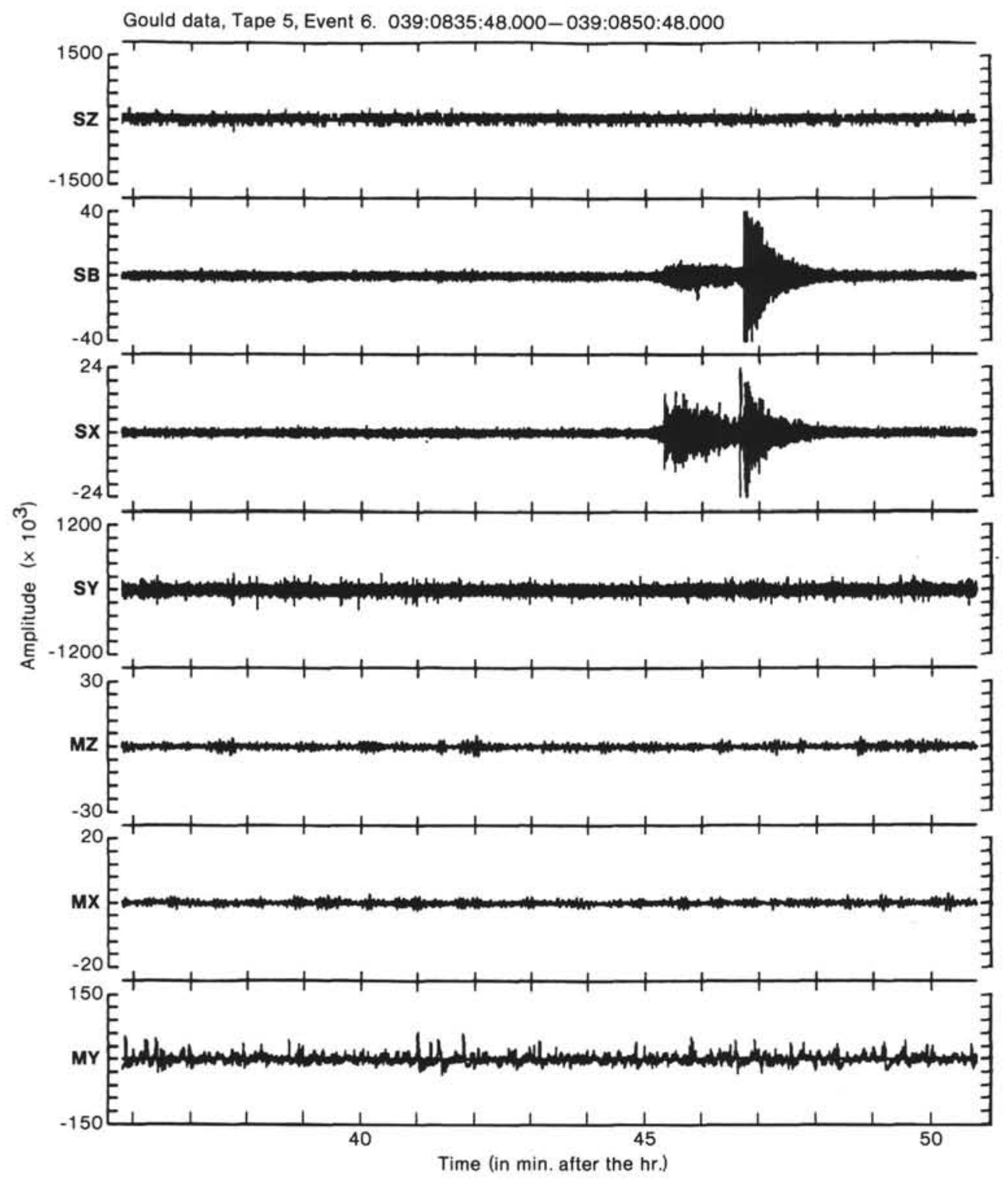

Figure 10. Typical example of seven-channel data from the Gould system. See Figure 9 for explanation. 

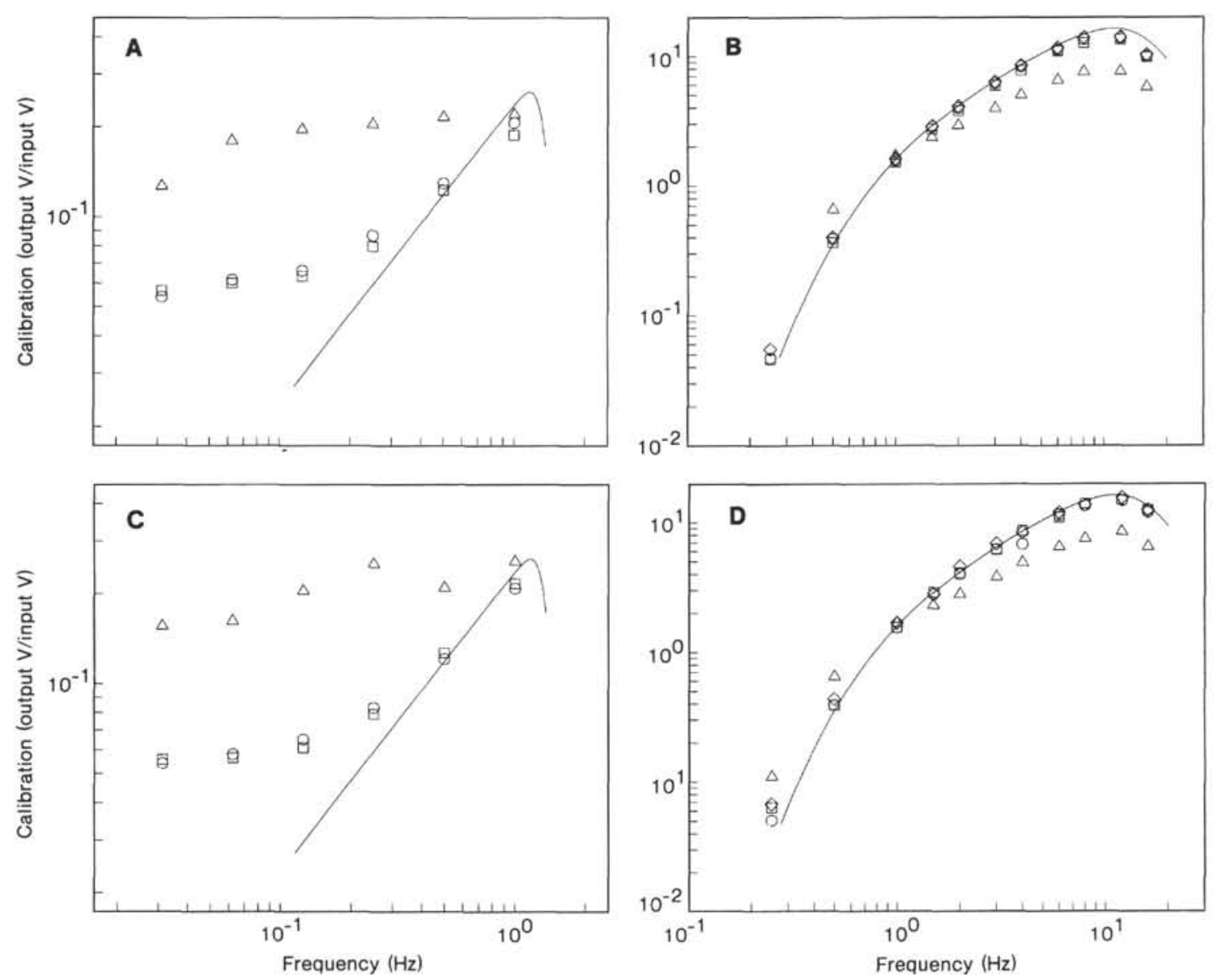

A, C: $\square M Z ; O M X: \triangle M Y$

B, D: $\square S Z ; O S X ; \triangle S Y ; \diamond S B$

Figure 11. MSS sensor calibrations recorded by the Teledyne system during the first (A, B) and second (C, D) shipboard recording periods. Channels $\mathrm{MZ}$ and $\mathrm{MX}$ were well-calibrated between 0.2 and $1.0 \mathrm{~Hz}(\mathrm{~A}, \mathrm{C})$, as were channels $\mathrm{SZ}, \mathrm{SX}$, and SB between 0.2 and $15 \mathrm{~Hz}$ (B, D). Y-sensor channels MY and SY were poorly calibrated at all times. 


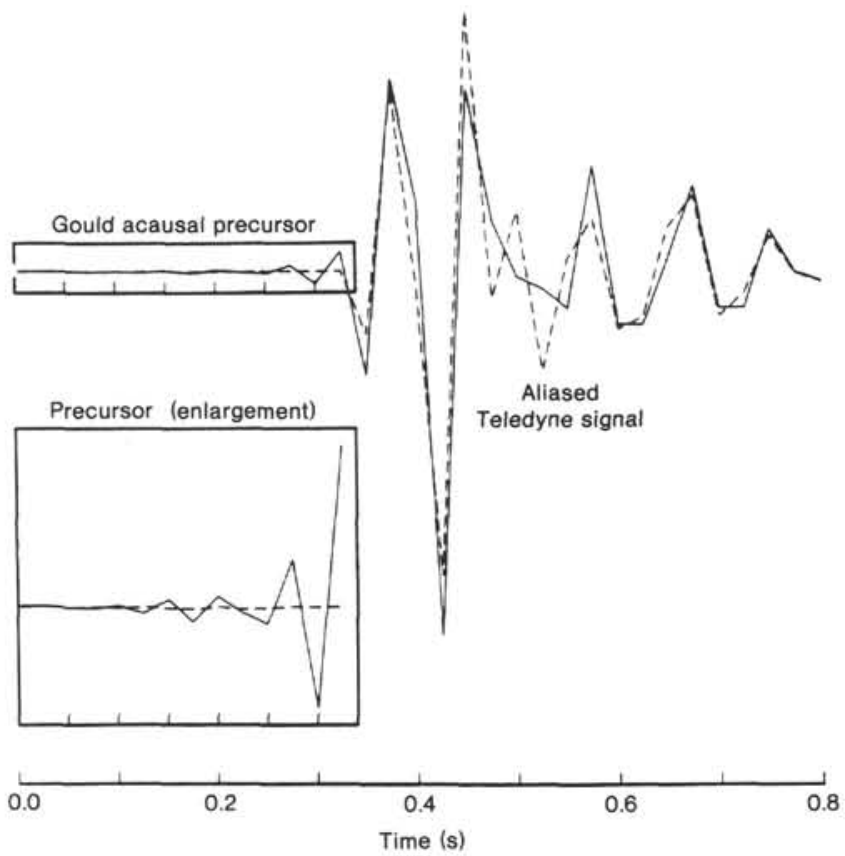

Figure 12. Illustration of the acausality caused by Gould's low-pass filter and of aliasing in the Teledyne data. Shown are simultaneous recordings on the Teledyne (dashed) and Gould (solid) systems of signals from a 1-lb shot, about 1920Z, 7 February 1983, detonated approximately $4 \mathrm{~km}$ from the borehole. The inset is an enlargement of the boxed portion of the seismogram section immediately above it. The time scale is given at the bottom . 